Article

\title{
Activation Energy and Second Order Slip in Bioconvection of Oldroyd-B Nanofluid over a Stretching Cylinder: A Proposed Mathematical Model
}

\author{
Iskander Tlili ${ }^{1,2, *}$, H. Waqas ${ }^{3}{ }^{(0)}$, Abulmajeed Almaneea ${ }^{4}$, Sami Ullah Khan ${ }^{5}$ and M. Imran ${ }^{3}$ (D) \\ 1 Department for Management of Science and Technology Development, Ton Duc Thang University, \\ Ho Chi Minh City 758307, Vietnam \\ 2 Faculty of Applied Sciences, Ton Duc Thang University, Ho Chi Minh City 758307, Vietnam \\ 3 Department of Mathematics, Government College University Faisalabad, Faisalabad 38000, Pakistan; \\ syedhasanwaqas@hotmail.com (H.W.); drmimranchaudhry@gmail.com (M.I.) \\ 4 Department of Mechanical Engineering, College of Engineering, Majmaah University, \\ Majmaah 11952, Saudi Arabia; a.almaneea@mu.edu.sa \\ 5 Department of Mathematics, COMSATS University Islamabad, Sahiwal 57000, Pakistan; sk_iiu@yahoo.com \\ * Correspondence: iskander.tlili@tdtu.edu.vn
}

Received: 9 October 2019; Accepted: 26 November 2019; Published: 3 December 2019

check for updates

\begin{abstract}
The thermal performances based on the interaction of nanoparticles are the topic of great interest in recent years. In the current continuation, we have utilized the activation energy and thermal radiation consequences in the bioconvection flow of magnetized Oldroyd-B nanoparticles over a stretching cylinder. As a novelty, the second order slip features (Wu's slip) and convective Nield boundary assumptions are also introduced for the flow situation. The heat performances of nanofluids are captured with an evaluation of the famous Buongiorno's model which enables us to determine the attractive features of Brownian motion and thermophoretic diffusion. The suggested thermal system is based on the flow velocity, nanoparticles temperature, nanoparticles volume fraction and motile microorganisms. The governing flow equations for the flow problem are constituted with relevant references for which numerically solution is developed via shooting algorithm. A detailed graphically analysis for the assisted flow problem is performed in view of the involved parameters. Although some studies are available in the literature which deals with the flow of various fluids over-stretching cylinder, the phenomenon of bioconvection and other interesting features are not reported yet. Therefore, present scientific computations are performed to fill this gap and the reported results can be more useful for the enhancement of thermal extrusion processes, solar energy systems, and biofuels.
\end{abstract}

Keywords: Oldroyd-B nanofluid; motile microorganisms; activation energy; stretching cylinder; shooting technique

\section{Introduction}

In order to enhance the consumption of fossil fuels and alleviating the environmental crises, modern nanotechnology suggested some effective resources based on the interaction of nanoparticles. In fact, the improvement of energy resources by using traditional techniques results in some serious environmental crunch like global warming, depletion of ozone layer and emission of $\mathrm{CO}_{2}$ and $\mathrm{CO}$. Therefore, scientists are devoted to providing renewable and clean sources for enhancement of energy to the society. On this end, nanofluids have been commenced to cope with this issue effectively. The nanoparticles, 
due to excellent thermophysical features are proffered for heat transfer performances associated with diverse engineering and mechanical industries. Owing to the higher thermal performances, the nanoparticles attain a valuable scientific significance in the field of engineering, chemical and mechanical industries and biomedical applications like diagnosis of various diseases, chemotherapy, artificial lungs, destroying of damage tissues, etc. The nanoparticles are a mixture of metallic particles with base liquid which was first suggested by Choi [1] in 1995. Based on experimental computations, Choi [1] proved that the thermal performance of relatively poor working liquid like water is enhanced with proper utilization of such nanoparticles. This amusing idea has been widely justified by numerous contributors in order to examine heat transportations in diverse flow situations. Later on, Buongiorno [2] determined the convective transport of nanoparticles with evaluation of Brownian motion and thermophoretic features. Azam et al. [3] utilized the slip features in the flow of Carreau nanoparticles over a moving configuration where non-similar computation has been carried out numerically. Alblawi and co-workers [4] addressed the thermophysical of nanoparticles by using Buongiorno nanofluid model in a curved stretched geometry. The interaction of four types of nanoparticles immersed in the base liquid with additional features of magnetic field was numerically attributed by Elgazery [5]. Hayat et al. [6] imposed the novel convective transport constraints for an unsteady flow of Jeffrey nanoparticles where solution was depicted via convergent algorithm. The Hall effects in the two-phase flow of dusty nanofluid have been reported by Gireesha and co-workers [7]. They used Khanafer-Vafai-Lightstone (LVL) model to distinguish the important consequences of effective thermal viscosity and nanoparticle viscosity. Hashim et al. [8] performed a numerical based continuation for the flow of non-Newtonian nanoparticles over a stretched surface. An interesting continuation in a similar direction was performed by Waqas et al. [9] which dealt with the flow of Maxwell viscoelasticity-based micropolar nanofluid over a porous surface. They developed a numerical solution for the dimensionless flow problem via shooting procedure. Turkyilmazoglu [10] examined the two-phase flow of nanoparticles over a circular jet. The peristaltic transport in the flow of nanoparticles under additional effects of hall and ion-slip was focused by Rafiq et al. [11]. Tlili et al. [12] simulated convective flow of nanoparticles in the circular cylinder influenced by applied magnetic force. Some more recent studies on this topic organized by numerous investigators can be found in references [13-18].

Recently, valuable work on the flow of non-Newtonian has been presented by various investigators because of their exceptional importance in various manufacturing and chemical industries, nuclear industries, bio-engineering, geophysics, and material processing. Many industrially important liquids like slurries, emulsion and polymer solutions attained a relatively convoluted rheological structure like shear thickening, shear-thinning, elasticity and extraordinary hardening associated with the flow. On this end, the importance of non-Newtonian fluids is still challenging and therefore, various non-Newtonian models are proposed in the literature to illustrate their complex rheological perspective. Among these non-Newtonian fluids, Oldroyd B is one that captures simultaneous relaxation and retardation features. Oldroyd B fluid also enables to explain of the creep and normal stress differences which is associated with simple shear flow. However, Oldroyd B fluid does not describe the shear thickening and shear thinning features, unlike other polymeric materials. Oldroyd-B fluid includes the substantial viscoelastic applications for Maxwell fluid and viscous fluid as a limiting case. Due to such prestigious consequences, a detailed scientific contribution based on the flow of Oldroyd-B fluid is inspected in the existed literature [19-26].

The macroscopic convective fluid particle movement results from the variation in the density gradient are termed as bioconvection. The macroscopic motion is encountered due to collective motile microorganisms swimming which altered the density of base fluid. The phenomenon of bioconvection accomplished wide range applications in biological sciences, biotechnology and bio-microsystems like enzyme biosensors and microfluidic devices. The bioconvection also plays a valuable role in mechanical engineering where an electric field is used to organize the bioconvection process for producing mechanical power resources and energy. Further, another attractive characteristic of 
bioconvection is when nanoparticles are accumulated with microorganisms, it enhanced the stability and mass transportation of nanoparticles. The first and foremost contribution to the bioconvection of microorganisms in existence of nanoparticles was successfully investigated by Kuznetsov [27,28]. Based on such useful contributions, it was verified that an enhanced truncation in the stability of nanoparticles may be possible via gyrotactic microorganisms phenomenon. Chakraborty et al. [29] added the effects of magnetic field in the bioconvection flow of nanoparticles considered over a convective heat configuration. The flow of nanofluid influenced by a strong magnetic force in the presence of gyrotactic microorganisms has been examined by Alsaedi et al. [30]. Another interesting work on this topic deals with the convective movement of nanoparticles which encountered the effects of gyrotactic microorganisms that have been determined numerically by Khan et al. [31]. Xun and co-workers [32] analyzed the combined features of time-dependent thermal conductivity and viscosity in bioconvection flow of nanofluid in a rotating frame. Beg et al. [33] find out the numerical simulations in the flow of non-Newtonian nanoparticles in a free stream where the effects of microorganisms are also utilized. Recently Waqas et al. [34] studied the phenomenon of motile gyrotactic microorganism in Falkner-Skan flow magnetized nanoparticles over a stretching surface. The thermally developed flow of Williamson nanoparticles in the presence of gyrotactic microorganisms and Newtonian boundary constraints was analyzed by Zaman and Gul [35]. Rehman et al. [36] summarized the flow of water-based nanoparticles with gyrotactic microorganisms over a vertically moving geometry. Bhatti et al. [37] simulate the flow of viscous nanoparticles over a stretching cylinder in the presence of thermal radiation and heat absorption/generation features.

After examining the literature survey presented above, it is noticed that no contribution has been devoted to revealing the flow of Oldroyd-B nanofluid over a stretched cylinder in the presence of gyrotactic microorganisms, activation energy, and thermal radiation effects. The proposed analysis has been performed with the simultaneous second order slip features and convective boundary assumptions [38-43]. The interaction of second order slip ( $\mathrm{Wu}^{\prime} \mathrm{s}$ slip) is quite different from the first order slip as it results two slip parameters that can effectively control the development in boundary layer. This condition is applied in order to make the model more realistic and practical. In fact, the present study is the extension of Irfan et al. [21] in three directions, first by considering the phenomenon of bioconvection, second by introducing the effects of activation energy and third by utilizing the second order slip features. The highly coupled nonlinear boundary value problem is numerically simulated with the shooting procedure. Later on, each physical parameter is expansively expressed with relative physical consequences.

\section{Physical Model}

We assume a two-dimensional radiative flow of Oldroyd-B fluid with addition of nanoparticles over a stretched cylinder of radius $R$. Following the cylindrical polar coordinates $(r, z)$, the $r$-axis is taken in the radial direction while $z$-axis is assumed along the cylinder axis. The effects of magnetic fields are utilized in $r$-axis. Owing to the smaller Reynolds number assumptions, the induced magnetic field effects are ignored (see Figure 1). Let $T, C$, and $N$ denotes the nanoparticles' temperature, concentration, and microorganism, respectively. The nanoparticles concentration and motile organisms near the surface are expressed with $C_{w}$ and $N_{w}$, respectively. Further, far away from the surface, the nanoparticles concentration is symbolized by $C_{\infty}$ and motile microorganisms is expressed by $N_{\infty}$. 


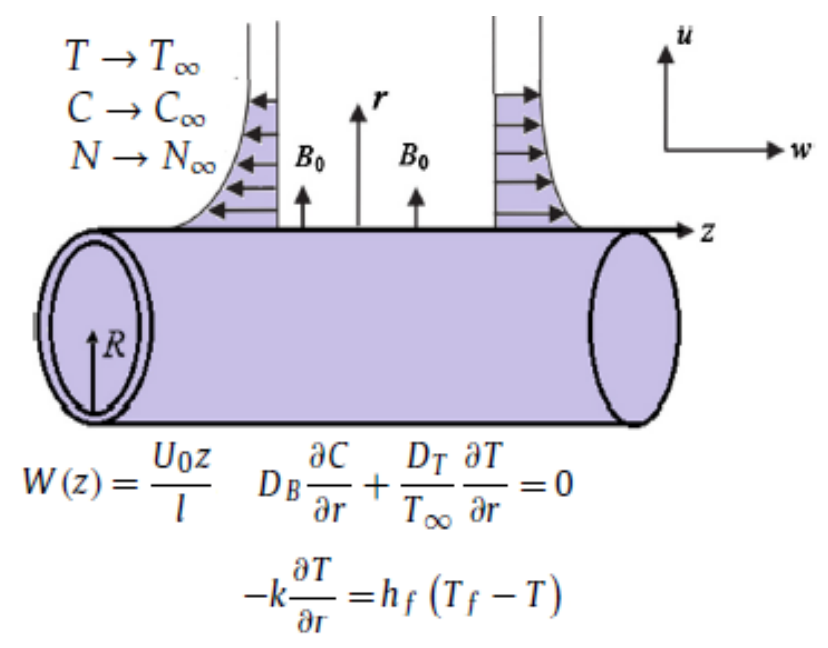

Figure 1. Geometry of the problem.

The constitutive equation for Oldroyd B fluid can be represented as [19].

$$
\begin{aligned}
T & =-p \mathbf{I}+\mathbf{S}, \\
\mathbf{S}+\lambda_{1} \frac{D \mathbf{S}}{D t} & =\mu\left(A_{1}+\lambda_{2} \frac{D A_{2}}{D t}\right),
\end{aligned}
$$

where $T$ is stress tensor, $p$ represents the pressure, $\mathbf{I}$ is identity vector, $\mathbf{S}$ relates the extra stress tensor, $\mu$ is dynamic viscosity, $\lambda_{1}$ relaxation time, $\lambda_{1}$ retardation time while $A_{1}$ is Rivlin-Ericksen tensor which is defined as

$$
\begin{gathered}
A_{1}=\nabla \mathbf{V}+(\nabla \mathbf{V})^{T}, \\
\mathbf{V}=[u, v, w],
\end{gathered}
$$

where $\mathbf{V}$ is the velocity vector. Since we have considered the steady-state flow problem, therefore, time derivative terms disappear. The continuity, momentum, thermal heat, concentration, and gyrotactic microorganism's equations are expressed as [21,37,44].

$$
\begin{aligned}
& \frac{\partial u}{\partial r}+\frac{u}{r}+\frac{\partial w}{\partial z}=0 \\
& u \frac{\partial w}{\partial r}+w \frac{\partial w}{\partial z}+\lambda_{1}\left[w^{2} \frac{\partial^{2} w}{\partial z^{2}}+u^{2} \frac{\partial^{2} w}{\partial r^{2}}+2 u w \frac{\partial^{2} w}{\partial r \partial z}\right]=v\left[\frac{\partial^{2} w}{\partial r^{2}}+\frac{1}{r} \frac{\partial w}{\partial r}\right]+\sigma B_{0}^{2}\left(-w-\lambda_{1} u \frac{\partial w}{\partial r}\right)+ \\
& v \lambda_{2}\left[\begin{array}{c}
\frac{u}{r^{2}} \frac{\partial w}{\partial r}-\frac{1}{r} \frac{\partial w}{\partial r} \frac{\partial w}{\partial z}-\frac{2}{r} \frac{\partial u}{\partial r} \frac{\partial w}{\partial r}+\frac{w}{r} \frac{\partial^{2} w}{\partial r \partial z}-\frac{\partial w}{\partial r} \frac{\partial^{2} w}{\partial r z z} \\
-2 \frac{\partial w}{\partial r} \frac{\partial^{2} u}{\partial r^{2}}+\frac{u}{r} \frac{\partial^{2} w}{\partial r^{2}}-\frac{\partial w}{\partial z} \frac{\partial^{2} w}{\partial r^{2}}+w \frac{\partial^{3} w}{\partial^{2} r \partial z}+u \frac{\partial^{3} w}{\partial r^{3}}
\end{array}\right]+\frac{1}{\rho_{f}}\left[\begin{array}{c}
\left(1-C_{\infty}\right) \rho_{f} \beta^{*} g\left(T-T_{\infty}\right)- \\
\left(\rho_{p}-\rho_{f}\right) g\left(C-C_{\infty}\right)- \\
\left(n-n_{\infty}\right) g \gamma^{*}\left(\rho_{m}-\rho_{f}\right)
\end{array}\right], \\
& u \frac{\partial T}{\partial r}+w \frac{\partial T}{\partial z}=\alpha_{1}\left[\frac{\partial^{2} T}{\partial r^{2}}+\frac{1}{r} \frac{\partial T}{\partial r}\right]+\tau\left[D_{B} \frac{\partial C}{\partial r} \frac{\partial T}{\partial r}+\frac{D_{T}}{T_{\infty}}\left(\frac{\partial T}{\partial r}\right)^{2}\right]-\frac{1}{(\rho c)_{f}} \frac{\partial\left(r q_{r}\right)}{\partial r}, \\
& u \frac{\partial C}{\partial r}+w \frac{\partial C}{\partial z}=D_{B} \frac{1}{r} \frac{\partial}{\partial r}\left(r \frac{\partial C}{\partial r}\right)+\frac{D_{T}}{T_{\infty}} \frac{1}{r} \frac{\partial}{\partial r}\left(r \frac{\partial T}{\partial r}\right)-K r^{2}\left(C-C_{\infty}\right)\left(\frac{T}{T_{\infty}}\right)^{2} \exp \left(\frac{-E_{a}}{k T}\right), \\
& u \frac{\partial N}{\partial r}+w \frac{\partial N}{\partial z}+\frac{b W_{c}}{\left(C_{w}-C_{\infty}\right)}\left[\frac{\partial}{\partial r}\left(N \frac{\partial C}{\partial r}\right)\right]=D_{m}\left(\frac{\partial^{2} N}{\partial r^{2}}\right),
\end{aligned}
$$

The developed flow is examined under the following boundary assumptions.

$$
w(r, z)=\frac{U_{0} z}{l}+u_{\text {slip }}, u(r, z)=0,-k \frac{\partial T}{\partial r}=h_{f}\left(T_{f}-T\right), D_{B} \frac{\partial C}{\partial r}+\frac{D_{T}}{T_{\infty}} \frac{\partial T}{\partial r}=0, N=N_{w} \text { at } r=R
$$




$$
w \rightarrow 0, T \rightarrow T_{\infty}, C \rightarrow C_{\infty}, N \rightarrow N_{\infty} \text { as } r \rightarrow \infty,
$$

We introduced the slip effects of the second order as follows [38-42].

$$
\begin{gathered}
u_{\text {slip }}=\frac{2}{3}\left(\frac{3-\alpha l^{2}}{\alpha}-\frac{3}{2} \frac{1-l^{2}}{K_{n}}\right) \beta \frac{\partial w}{\partial r}-\frac{1}{4}\left[l^{4}+\frac{2}{K_{n}^{2}}\left(1-l^{2}\right)\right] \beta^{2} \frac{\partial^{2} w}{\partial r^{2}}, \\
u_{\text {slip }}=A^{*} \frac{\partial w}{\partial r}+B^{*} \frac{\partial^{2} w}{\partial r^{2}}
\end{gathered}
$$

where $\lambda_{1}$ is the relaxation time coefficient, $\lambda_{2}$ represents the retardation time, $B$ is magnetic field strength, $\sigma$ denotes electrical conductivity, $g$ is gravity, $\rho_{p}$ stands for liquid density, $\rho_{m}$ signify motile microorganism particles density, $C$ determine volume concentration of magnetic particles, $N$ is density of microorganism, $T_{f}$ represents the convective fluid temperature, $h_{f}$ is heat transfer coefficient, $\rho_{f}$ determine nanoparticles density, $T$ is nanoparticles temperature, $\alpha_{1}$ is thermal diffusivity, $D_{B}$ being Brownian motion constant, $D_{T}$ thermophoretic diffusion coefficient, $W_{c}$ speed of gyrotactic cell, $K_{n}$ notify the Knudsen number, $A$ and $B$ stands for constant, $b_{1}$ chemotaxis constant, $\beta$ molecular mean path, $\alpha$ accomplished momentum coefficient. It is remarked that second order slip appeared in Equation (8) is termed as Wu's slip condition which has already been used by numerous researchers [38-42].

In order to modify Equation (7) for thermally developed flow, the expression based on Rosseland approximation can be expressed as [22].

$$
q_{r}=-\frac{16 \sigma^{* *} T_{\infty}^{3}}{3 k^{* *}}\left(\frac{\partial T}{\partial r}\right)
$$

where $\sigma^{* *}$ is the Stefan-Boltzmann constant while $k^{* *}$ represents the mean absorption coefficient.

Before computing the numerical solution, let us convert the flow equations in dimensionless form by inserting the following variables $[21,37,43,44]$.

$$
\begin{aligned}
& u=-\frac{R}{r} \sqrt{\frac{U_{0} v}{l}} f(\zeta), w=\frac{U_{0} z}{l} f^{\prime}(\zeta), \theta(\zeta)=\frac{T-T_{\infty}}{T_{f}-T_{\infty}}, \\
& \left.\phi(\zeta)=\frac{C-C_{\infty}}{C_{w}}, \chi(\zeta)=\frac{N-N_{\infty}}{N_{w}-N_{\infty}}, \zeta=\sqrt{\frac{U_{0}}{v l}}\left(\frac{r^{2}-R^{2}}{2 R}\right)\right\}
\end{aligned}
$$

where $\zeta$ is similarity variable, $l$ is the characteristic length while $f, f^{\prime}, \theta, \phi$ and $\chi$ are dimensionless quantities. Operated above transformations in the governing flow equations, we result in following dimensionless forms $[21,37,44]$.

$$
\begin{gathered}
(1+2 \alpha \zeta) f^{\prime \prime \prime}+2 \alpha f^{\prime \prime}+f f^{\prime \prime}-f^{2}+2 \beta_{1} f^{2} f^{\prime \prime \prime}-\frac{\alpha \beta_{1}}{(1+2 \alpha \zeta)} f^{2} f^{\prime \prime}+(1+2 \alpha \zeta) \beta_{2}\left(f^{\prime \prime 2}-f f^{i v}\right) \\
-4 \alpha \beta_{2} f f^{\prime \prime \prime}-M^{2}\left(f^{\prime}-\beta_{1} f f^{\prime \prime}\right)+\Gamma(\theta-N r \phi-N c \chi)=0 \\
\left(1+\frac{4 R}{3}\right)\left[(1+2 \alpha \zeta) \theta^{\prime \prime}+2 \alpha \theta^{\prime}\right]+{ }_{n} f \theta^{\prime}+(1+2 \alpha \zeta) N b \theta^{\prime} \phi^{\prime}+(1+2 \alpha \zeta) N t \theta^{\prime 2}+{ }_{n}\left[\delta f^{\prime}+\delta_{1} \theta\right]=0 \\
(1+2 \alpha \zeta) \theta^{\prime \prime}+2 \alpha \theta^{\prime}+L e . f \theta^{\prime}+(1+2 \alpha \zeta)\left(\frac{N t}{N b}\right) \theta^{\prime \prime}+2 \alpha\left(\frac{N t}{N b}\right) \theta^{\prime}-L e \sigma(1+\delta \theta)^{n} \exp \left(\frac{-E}{1+\delta \theta}\right) \phi=0 \\
(1+2 \alpha \zeta) \chi^{\prime \prime}+L b[(1+2 \alpha \zeta)(f \prime \chi)]-P e\left[\phi^{\prime \prime}\left(\chi+\Omega_{1}\right)+\chi \chi^{\prime} \phi^{\prime}\right]=0 \\
f(0)=0, \quad f \prime(0)=1+\omega f^{\prime \prime}(0)+\Omega f^{\prime \prime \prime}(0), \theta \prime(0)=B i(\theta(0)-1), N b \theta \prime(0)+N t \phi \prime(0)=0, \chi(0)=1 \\
f \prime \rightarrow 0, \quad \theta \rightarrow 0, \phi \rightarrow 0, \chi \rightarrow 0 \text { as } \zeta \rightarrow \infty
\end{gathered}
$$

where $\alpha\left(=\frac{1}{R} \sqrt{\frac{v l}{U_{0}}}\right)$ is constant curvature parameter, $\beta_{1}\left(=\frac{\lambda_{1} U_{0}}{l}\right)$ denotes the Deborah number in terms of relaxation time [31], $\beta_{2}\left(=\frac{\lambda_{2} U_{0}}{l}\right)$ is Deborah number in terms of retardation time, $M\left(=\frac{\sigma B_{0}^{2} l}{U_{0} \rho_{f}}\right)$ Hartmann number, $\Gamma=\frac{\beta^{*}\left(1-C_{\infty}\right)\left(T_{w}-T_{\infty}\right)}{U_{0}^{2}}$ mixed convection parameter, $N c=\frac{\gamma\left(\rho_{m}-\rho_{f}\right)\left(N_{w}-N_{\infty}\right)}{\left(1-C_{\infty}\right)\left(T_{w w}-T_{\infty}\right) \beta^{*}}$ Rayleigh 
number, $N_{r}=\frac{\left(\rho_{p}-\rho_{f}\right)\left(C_{w}-C_{\infty}\right)}{\left(1-C_{\infty}\right)\left(T_{w}-T_{\infty}\right) \beta^{*}}$ is buoyancy ratio constant, $N t\left(=\frac{\tau D_{T}\left(T_{f}-T_{\infty}\right.}{v T_{\infty}}\right)$ thermophoresis parameter, $\mathrm{Nb}\left(=\frac{\tau D_{B}\left(C_{w}\right)}{v}\right)$ denoted the Brownian motion, $R\left(=\frac{4 \sigma^{* *} T_{\infty}^{*}}{k k^{* *}}\right)$ thermal radiation parameter, $\operatorname{Pr}\left(=\frac{v}{\alpha_{1}}\right)$ is Prandtl number, $L e\left(=\frac{\alpha_{1}}{D_{B}}\right)$ is the Lewis number, $\gamma\left(=\frac{h_{f}}{k} \sqrt{\frac{v l}{U_{0}}}\right)$ denotes the Biot number, $P e=\frac{b W_{c}}{D_{m}}$ is the Peclet constant, $L b=\frac{v}{D_{m}}$ Lewis number, $\Omega_{1}=\frac{N_{\infty}}{N_{w}-N_{\infty}}$ is bioconvection constant, $\omega=A^{*}\left(\frac{r}{R}\right) \sqrt{\frac{U_{0}}{2 l}}$ is the first order slip constant while $\Omega=B^{*}\left(\frac{r}{R}\right) \sqrt{\frac{U_{0}}{2 l}}$ determines the second order slip constant.

It is remarked that for $\beta_{2}=0$, the fluid model is converted to Maxwell fluid model while $\beta_{1}=\beta_{2}=0$ results viscous case.

In order to determine the rate of heat transfer, rate of mass transfer and gyrotactic microorganism transfer, we defined local Nusselt number, local Sherwood number and motile density number with following expressions:

$$
N u_{z}=\frac{z q_{l}}{k\left(T_{f}-T_{\infty}\right)}, S h_{z}=\frac{z j_{l}}{D_{B}\left(C_{w}-C_{\infty}\right)}, N x_{z}=\frac{z j_{n}}{D_{B}\left(N_{w}-N_{\infty}\right)},
$$

where $q_{l}$ is symbolized as heat flux, $j_{l}$ is mass flux and $j_{n}$ represents the motile flux, which are defined below

$$
\begin{gathered}
q_{l}=-\frac{16 \sigma^{* *} T_{\infty}^{3}}{3 k^{* *}}\left(\frac{\partial T}{\partial r}\right)_{r=R}, j_{l}=-D_{B}\left(\frac{\partial C}{\partial r}\right)_{r=R}, j_{n}=-D_{B}\left(\frac{\partial N}{\partial r}\right)_{r=R}, \\
N u_{x} \operatorname{Re}_{x}^{-\frac{1}{2}}=-\theta \prime(0), S h_{x} \operatorname{Re}_{x}^{-\frac{1}{2}}=-\phi \prime(0), N n_{x} \operatorname{Re}_{x}^{-\frac{1}{2}}=-\chi \prime(0) .
\end{gathered}
$$

where $\operatorname{Re}_{x}^{-1 / 2}=w(z) z / v$ is the Reynolds number [21], $N u_{x}$ is local Nusselt number, $S h_{x}$ is local Sherwood number while $N n_{x}$ determined the motile density number.

\section{Numerical Computations}

Since dimensionless Equations (16)-(19) are highly nonlinear in nature, therefore the exact solution is quite challenging. On this end, we employ a famous numerically based shooting procedure to simulate the numerical solution. To start simulations, we first convert the dimensionless boundary value flow problem into initial value problems as follows:

$$
\begin{aligned}
& f=r_{1}, \frac{d f}{d \zeta}=r_{2}, \frac{d^{2} f}{d \zeta^{2}}=r_{3}, \frac{d^{3} f}{d \zeta^{3}}=r_{4}, \frac{d^{4} f}{d \zeta^{4}}=r_{4^{\prime}}^{\prime}, \theta=r_{5}, \frac{d \theta}{d \zeta}=r_{6}, \frac{d^{2} \theta}{d \zeta^{2}}=r_{6^{\prime}}^{\prime} \\
& \phi=r_{7}, \frac{d \phi}{d \zeta}=r_{8}, \frac{d^{2} \phi}{d \zeta^{2}}=r_{8}^{\prime}, \chi=r_{9}, \frac{d \chi}{d \zeta}=r_{10}, \frac{d^{2} \chi}{d \zeta^{2}}=r_{10^{\prime}}^{\prime} \\
& \frac{d f}{d \zeta}=r_{2}, \frac{d^{2} f}{d \zeta^{2}}=r_{3}, \frac{d^{3} f}{d \zeta^{3}}=r_{4}, \frac{d^{4} f}{d \zeta^{4}}=r_{4^{\prime}}^{\prime} \\
& y_{4}^{\prime}=\frac{\left(\begin{array}{c}
(1+2 \alpha \zeta) r_{4}+2 \alpha r_{3}-r_{2}^{2}-2 \beta_{1} r_{1} r_{2} r_{3}-\beta_{1} r_{1}^{2} r_{4}-\left(\frac{\alpha \beta_{1}}{1+2 \alpha \zeta}\right) \\
+(1+2 \alpha \zeta) \beta_{2} r_{3}{ }^{2}-4 \alpha \beta_{2} r_{1} r_{4}-M\left(r_{2}-\beta_{1} r_{1} r_{3}\right)-\lambda\left(y_{5}-N r y_{7}-N c y_{9}\right)
\end{array}\right)}{(1+2 \alpha \zeta) \beta_{2} r_{1}} \\
& \theta=r_{5}, \frac{d \theta}{d \zeta}=r_{6}, \frac{d^{2} \theta}{d \zeta^{2}}=r_{6}^{\prime} \\
& r_{6}^{\prime}=-\frac{1}{\left(1+\frac{4}{3} R d\right)}\left[\operatorname{Pr} r_{1} r_{6}+\operatorname{Pr}(1+2 \alpha \zeta) N b r_{5} r_{7}+\operatorname{Pr}(1+2 \alpha \zeta) N t r_{6}^{2}\right] \\
& \phi=r_{7}, \frac{d \phi}{d \zeta}=r_{8}, \frac{d^{2} \phi}{d \zeta^{2}}=r_{8}^{\prime} \\
& (1+2 \alpha \eta) \theta^{\prime \prime}+2 \alpha \theta^{\prime}+L e \operatorname{Pr} f \theta^{\prime}+(1+2 \alpha \eta)\left(\frac{N t}{N b}\right) \theta^{\prime \prime}+2 \alpha\left(\frac{N t}{N b}\right) \theta^{\prime} \\
& -\operatorname{PrLe\sigma }(1+\delta \theta)^{n} \exp \left(\frac{-E}{1+\delta \theta}\right) \phi=0 \text {, } \\
& r_{8}^{\prime}=\frac{1}{(1+2 \alpha \zeta)}\left[\begin{array}{c}
-(1+2 \alpha \zeta)\left(\frac{N t}{N b}\right) r_{6}{ }^{\prime}-2 \alpha\left(\frac{N t}{N b}\right) r_{6}-\operatorname{PrLer}_{1} r_{8} \\
+L e \operatorname{Pr}\left(\sigma\left(1+\delta r_{5}\right)^{n} \exp \left(\frac{-E}{1+\delta r_{5}}\right)\right) r_{7}
\end{array}\right], \\
& \chi=r_{9}, \frac{d \chi}{d \zeta}=r_{10}, \frac{d^{2} \chi}{d \zeta^{2}}=r_{10^{\prime}}^{\prime} \\
& r_{10}^{\prime}=\frac{1}{(1+2 \alpha \zeta)} \operatorname{Pe}\left[r_{8}^{\prime}\left(r_{9}+\Omega_{1}\right)+r_{10} r_{8}\right]-L b(1+2 \alpha \zeta) r_{1} r_{10}
\end{aligned}
$$


The transformed conditions are

$$
\left.\begin{array}{c}
r_{1}(\zeta)=0, r_{2}(\zeta)-\left(1+\gamma r_{3}(\zeta)+\delta r_{4}(\zeta)\right), r_{6}(\zeta)-B i\left(r_{5}(\zeta)-1\right)=0, \\
N b r_{6}(\zeta)+N r_{8}(\zeta)=0, r_{9}(\zeta)=1, \text { as } \zeta=0,
\end{array}\right\}
$$

Following the iterative procedure, the solution is accurate up to convincing accuracy of $10^{-4}$. The step size for present simulation is taken as $\Delta \xi=1 \times 10^{-4}$.

\section{Validation of Result}

In order to verify the solution, the present results are compared with Abel et al. [42], Megahed [43] and Iran et al. [43] in Table 1. It is easily noted that the obtained numerical results have an excellent agreement between these reported results.

Table 1. Comparison of $-f^{\prime \prime}(0)$ for different $\beta_{1}$ in limiting cases when $\alpha=0, \beta_{2}=0, N r=0, N c=0$, $\Gamma=0$ and $M=0$.

\begin{tabular}{ccccc}
\hline \multirow{2}{*}{$\boldsymbol{\beta}_{1}$} & \multicolumn{3}{c}{$-f^{\prime \prime}(0)$} & \multirow{2}{*}{ Present Results } \\
\cline { 2 - 4 } & Reference [42] & Reference [43] & Reference [44] & \\
\hline 0.0 & 0.999978 & 1.000000 & 1.000000 & 1.000000 \\
0.2 & 1.051945 & 1.051889 & 1.0518898 & 1.0518899 \\
0.4 & 1.101848 & 1.101903 & 1.1019033 & 1.1019033 \\
\hline
\end{tabular}

\section{Analysis of Results}

After successfully computing the numerical simulation [45-52], now we examine the flow mechanism of various engineering parameters like constant curvature parameter $\alpha$, Deborah number in terms of relaxation time $\beta_{1}$, Deborah number in terms of retardation time $\beta_{2}$, Hartmann number $M$, mixed convection parameter $\Gamma$, Rayleigh number $N c$, buoyancy ratio constant $N r$, thermophoresis parameter $N t$, Brownian motion $N b$, thermal radiation parameter $R$, Prandtl number Pr, Lewis number $L e$, Biot number $\gamma$, Peclet constant $P e$, Lewis number $L b$, bioconvection constant $\Omega_{1}$, first order slip constant $\omega$ and second order slip parameter $\Omega$ on the distribution of velocity $f^{\prime}$, temperature $\theta$, concentration $\phi$ and motile microorganisms $\chi$. Following to the traditional theoretical scientific contributions for similar analysis, we have allocated some fixed value to each physical parameter like $\alpha=0.1, \beta_{1}=0.2, \beta_{2}=0.1, M=0.5, \Gamma=0.2, N c=0.2, N r=0.3, N t=0.4, N b=0.4, R=0.6$, $\operatorname{Pr}=0.71, L e=0.3, \gamma=0.3, P e=0.2, L b=0.4, \Omega_{1}=0.1, \omega=0.2$ and $\Omega=0.3$. It is remarked that for present flow problem, the viscosity of fluid is assumed to be constant and all the graphical analysis has been performed with this fact for all parameters. The physical illustration of Hartmann number $M$ and mixed convection parameter $\Gamma$ on $f$, has been visualized in Figure 2 . The velocity distribution truncated with $M$ as being an interaction of Lorentz force which is of resistive nature and subsequently reduced the movement of fluid particles. On contrary, an enhanced distribution of $f \prime$ has been observed for leading values of $\Gamma$. The graphical computations are performed in Figure 3 which deals with the impact first order slip parameter $\Omega$ and buoyancy ratio parameter $N r$ on $f$ '. With variation of $N r$, the alteration in $f$, shows a decreasing trend due to presence of buoyancy forces which retarded the movement of fluid particles effectively. Similarly, the presence of the slip factor also declined the velocity of the particles near the surface. Figure 4 depicts the variation for the progressive values of Rayleigh number $N c$ and second order slip factor $\omega$ on velocity distribution $f \prime$. With variation of both parameters, a decrement in the velocity distribution is observed. With utilization of second order slip consequences also leads to being a depressed velocity profile. 


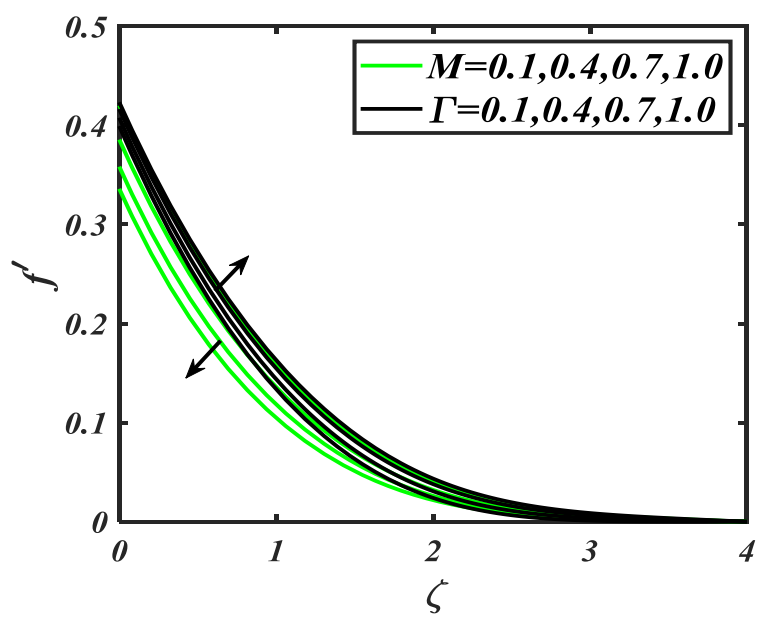

Figure 2. Effects of $M$ and $\Gamma$ on $f^{\prime}$.

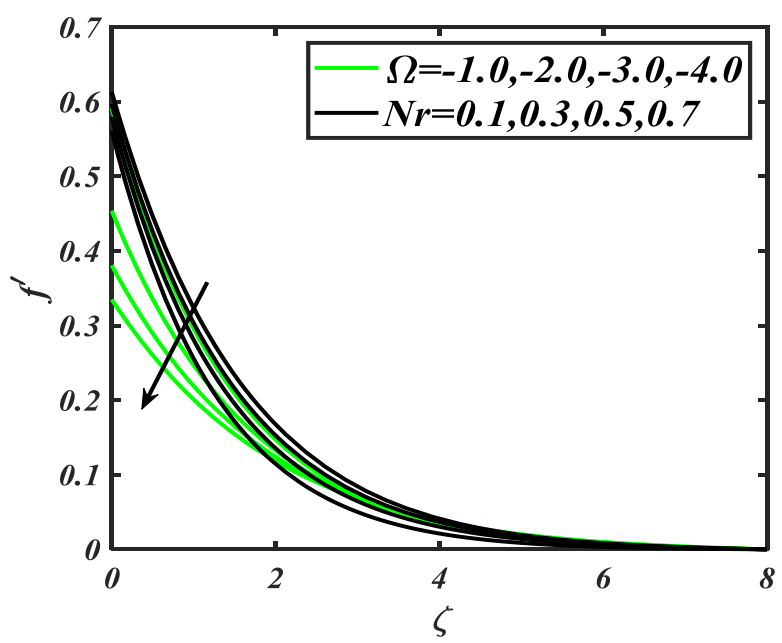

Figure 3. Effects of $\Omega$ and $N r$ on $f^{\prime}$.

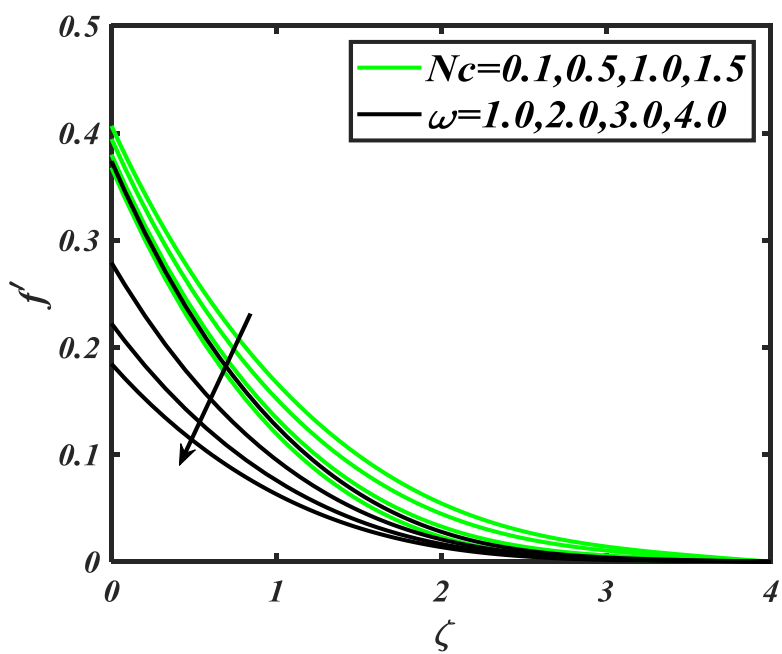

Figure 4. Of $N c$ and $\omega$ on $f^{\prime}$.

In order to examine the fluctuation in nanoparticle temperature $\theta$ against different values of Hartmann number $M$ and mix convection parameter $\Gamma$, Figure 5 is presented. While observing the variation in $\theta$ with $M$, an improved nanoparticle temperature is originated due to the evaluation of Lorentz force. The implementation of a strong magnetic force slightly enhanced the nanoparticles' 
temperature and concerned boundary layer. However, quite opposite observations were being found due to the alteration of $\Gamma$. The mixed convection parameter is usually related to the Grashoff number which boosts up nanoparticle temperature efficiently.

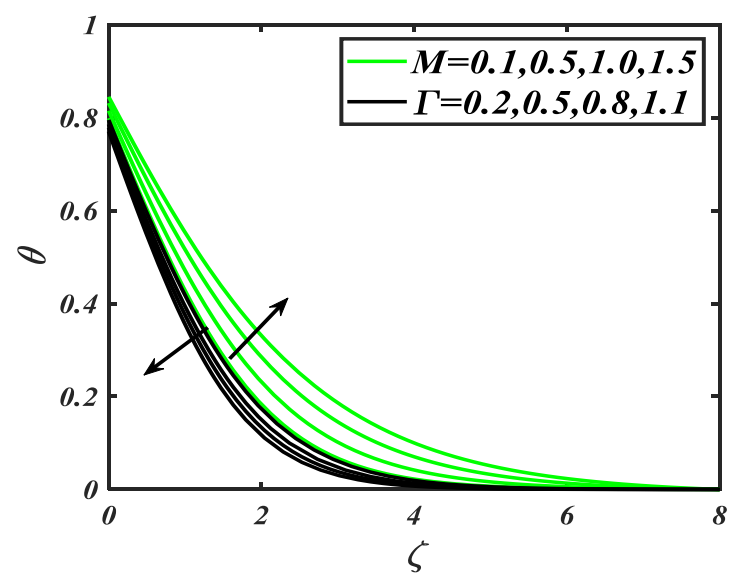

Figure 5. Of $M$ and $\Gamma$ on $\theta$.

Figure 6 intrigued the influence of the thermophoresis parameter $N t$ and first order slip parameter $\omega$ on $\theta$. A progressive nanoparticles distribution was observed for $N t$. However, change in nanoparticle temperature was quite minimal due to the occurrence of smaller temperature difference. Physically, thermophoresis process was a migration of fluid particles from the hot configuration to the relatively cold region. Due to such fluctuation of nanoparticles, temperature profile enhanced. Another interesting observation examined for the variation of the slip constant reveals that the presence of the slip parameter also played a collective role in the enhancement of thermo-physical systems. Figure 7 designed the envision of nanoparticle temperature $\theta$ for leading values of curvature parameter $\alpha_{1}$ and Prandtl number $P r$. With increasing $\alpha_{1}$, distribution of $\theta$ enlarged maximum values. The variation in $\theta$, due to existing values of $\operatorname{Pr}$, controled the nanoparticles' temperature as $\operatorname{Pr}$ attained inverse relation with thermal diffusivity. The variation in thermal diffusivity becomes slower as $\operatorname{Pr}$ gets maximum values. The graphical explorations are portrayed in Figure 8 to depress the impact of Biot number $B i$ and Radiation parameter $R d$ on $\theta$. A boosting nanoparticles temperature has been examined with involvement of $R d$. Physically, the enrolment of radiation parameter provided extra heat to the nanoparticles' temperature due to which temperature increases. While observing the role of thermal Biot number $B i$. on $\theta$, we note that an upshot of nanoparticles was exhibited due to large $B i$. The physical justification behind such a trend was justified as $B i$, directly related to the coefficient of heat transfer which results in an increased temperature distribution. Moreover, more heat is transmuted from the hot surface to cold region particles which raise the temperature distribution.

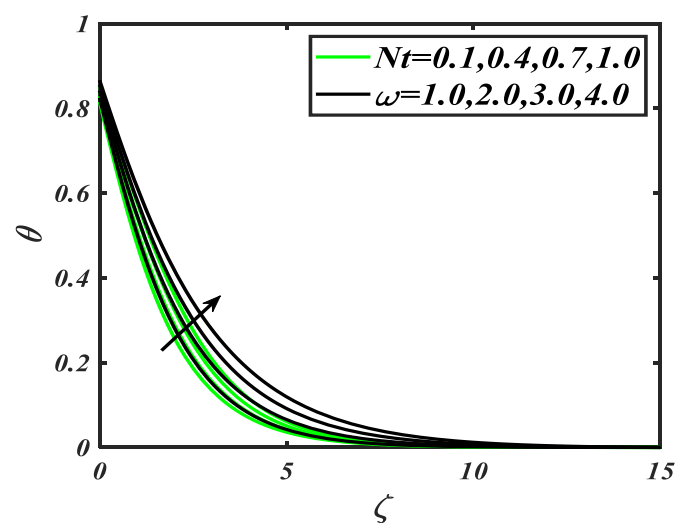

Figure 6. Of $N t$ and $\omega$ on $\theta$. 


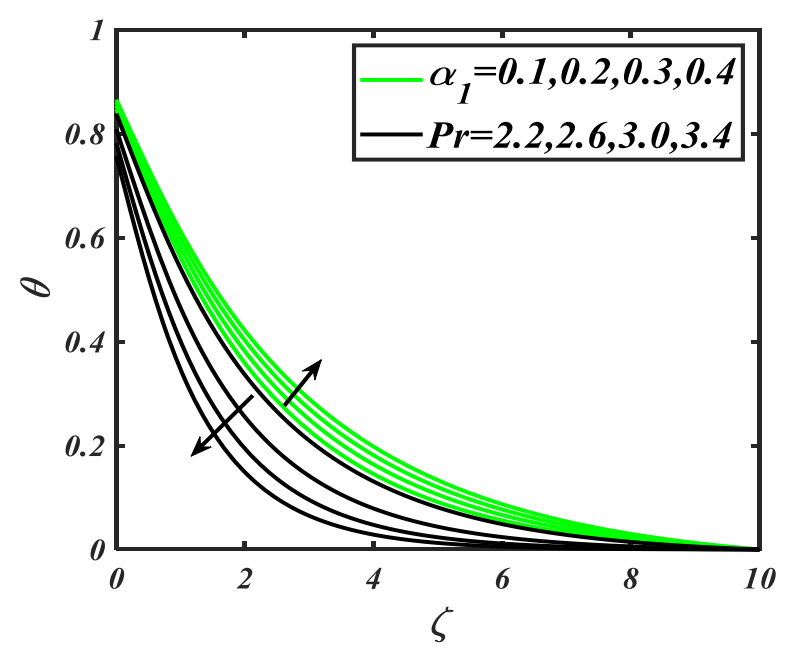

Figure 7. Effects of $\alpha_{1}$ and $\operatorname{Pr}$ on $\theta$.

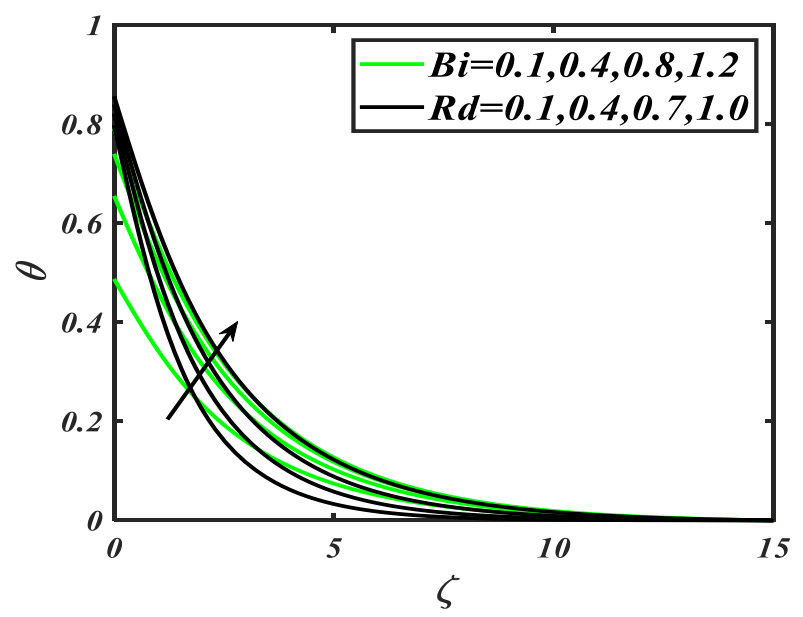

Figure 8. Of $B i$ and $R d$ on $\theta$.

Figure 9 illustrates the effect of thermophoresis $N t$ and second order slip parameter $\omega$ on volume fraction concentration distribution $\phi$. We have examined that nanoparticles concentration $\phi$. slightly enhanced with $N t$. While examining the variation of $\omega$ on $\phi .$, it was noted that the concentration distribution had again fluctuated with leading values of $\omega$ effectively. However, the increasing trend in $\phi$. was relatively slower for $\omega$ as compared to the $N t$. The combined effect of activation energy $E$ and Prandtl number Pr on concentration distribution $\phi$ is discussed in Figure 10. The activation energy was the minimum energy amount to start the reaction process. Therefore, while increasing activation energy, the reaction process increased, which enhanced the concentration distribution $\phi$. Such results could play useful role in processes where the reaction process needs to be improved. On the other hand, the Prandtl number controlled the concentration distribution. With increase of Pr, the nanoparticles concentration declined. Figure 11 illustrates the behavior of Hartmann's number $M$ and mix convection parameter $\Gamma$ on concentration field $\phi$. It was noted that concentration distribution is increased with increase of $M$. Due to magnetization of nanoparticles, the concentration distribution was altered with specified range. Physically, the Hartmann number is associated with large Lorentz force which reduced the velocity of nanoparticles but enhanced the nanoparticle concentration. However, the effects of mixed convection constant $\Gamma$ were quite opposite i.e., concentration profile decay for leading values of $\Gamma$. Figure 12 exposed the impact of Brownian motion constant $\mathrm{Nb}$ and Lewis number $L e$ on $\phi$. It is noteworthy that both the parameters decreased the function of concentration field. The Brownian motion constant involves the random movement of fluid particles in the whole system which is truncated as $\mathrm{Nb}$ get maximum values. Further $\mathrm{Nb}$ appeared in $(1 / \mathrm{Nb})$ form the formulated 
dimensionless concentration equation due to which $\phi$ declined. It is remarked that negative values to concentration distribution do not mean that concentration is negative but magnitude of concentration is positive. Similar trend of concentration distribution has been found in Atif et al. [45].

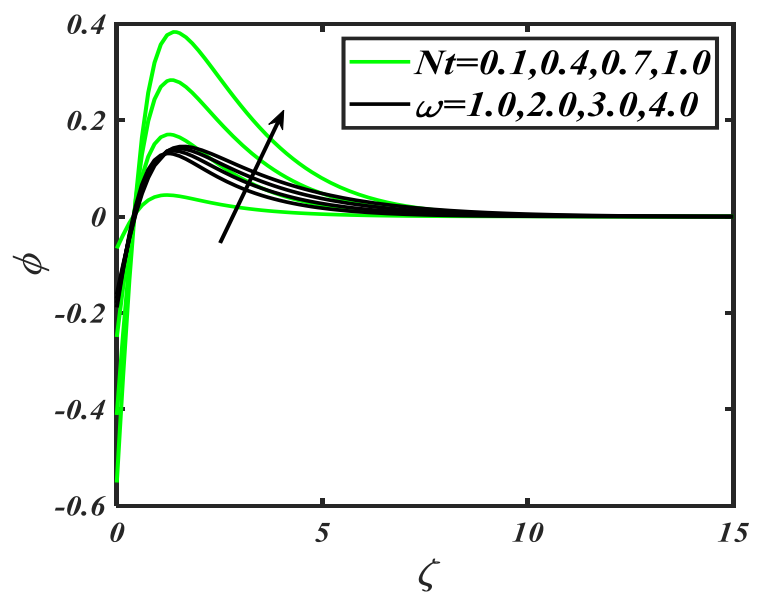

Figure 9. Of $N t$ and $\omega$ on $\phi$.

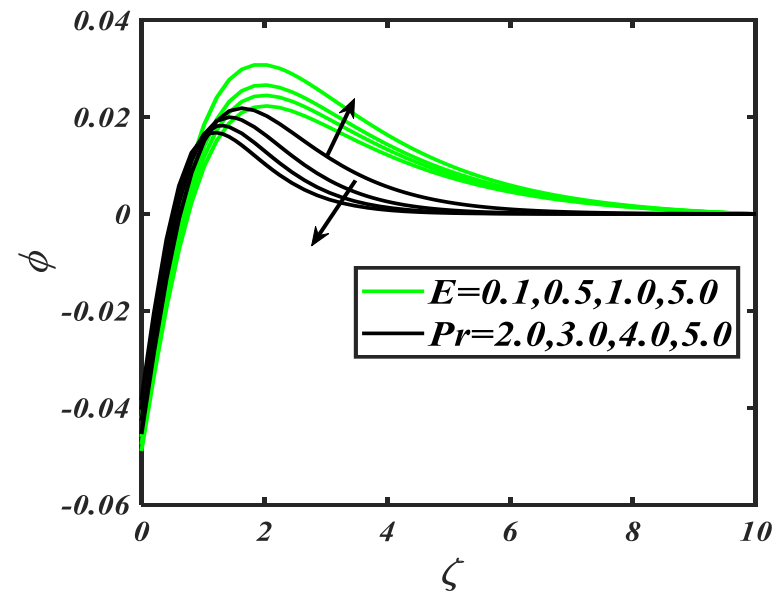

Figure 10. Of $E$ and $\operatorname{Pr}$ on $\phi$.

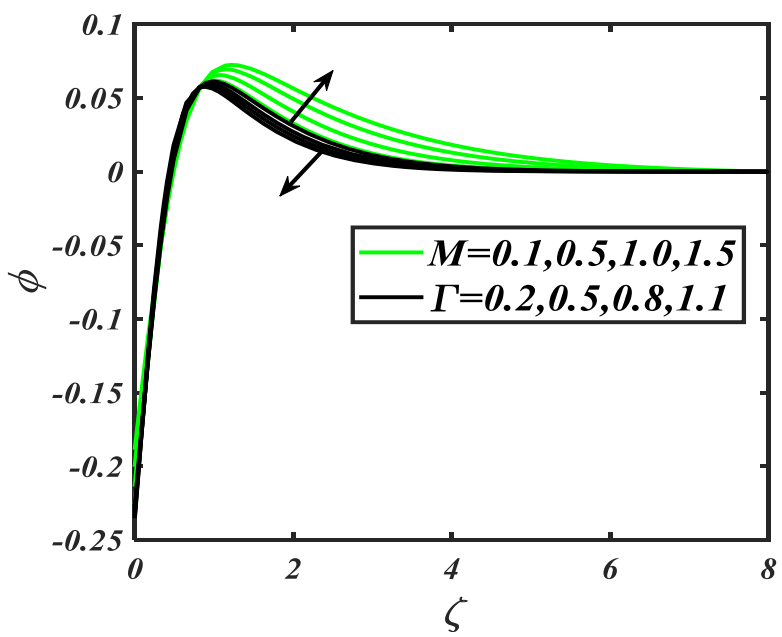

Figure 11. Of $M$ and $\Gamma$ on $\phi$. 


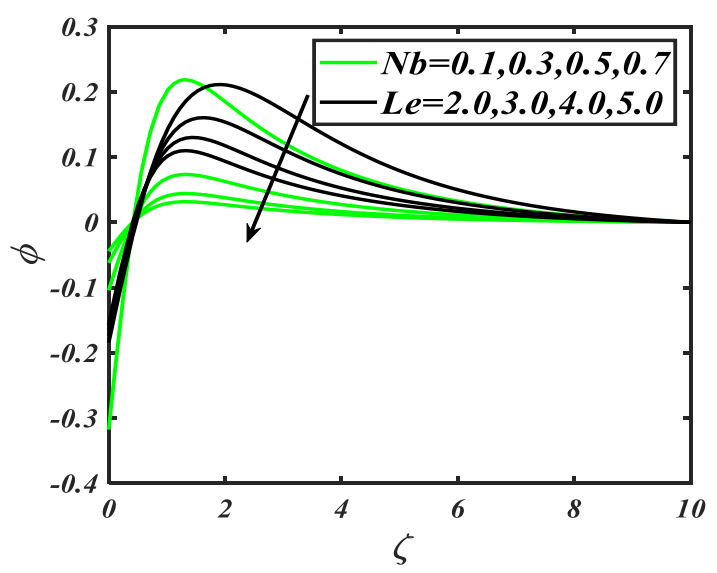

Figure 12. Of $\mathrm{Nb}$ and $L e$ on $\phi$.

The variation in $X$ for various values of Hartmann number $M$ mixed convection parameter $\Gamma$ Peclet number $P e$ and bioconvection Lewis number $L b$ has been inspected in Figures 13 and 14 . Figure 13 deals with the variation of Hartmann number $M$ and mixed convection parameter $\Gamma$ on motile density profile $\chi$ The motile organism profile sufficiently improved with $M$ however, a decrement in $\chi$ has been noted for $\Gamma$ To determine the effects of Peclet number $P e$ and bioconvection Lewis number $L b$ on motile microorganism distribution $\chi$, Figure 14 is sketched. The maximum values of $P e$ results decrement of microorganisms diffusivity and so $X$ declined. Moreover, it can be also observed that increasing values of bioconvection Lewis number $L b$ also causes lower motile microorganism distribution $X$.

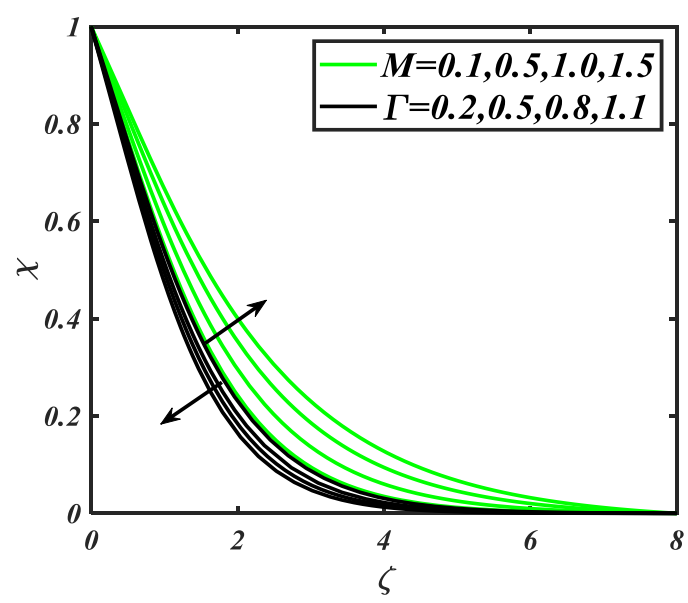

Figure 13. Of $M$ and $\Gamma$ on $\phi$.

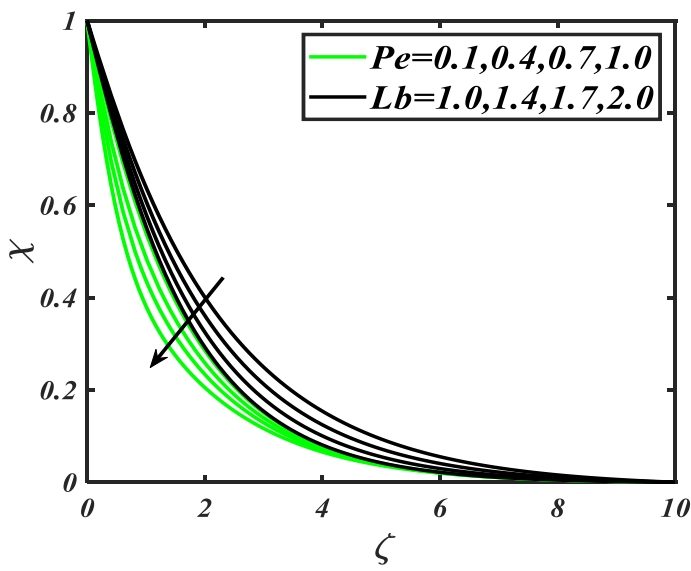

Figure 14. Of $P e$ and $L b$ on $\phi$. 
Table 2 presents the numerical variation in $-f^{\prime \prime}(0)$ for different values assigned to the various parameters like $M, \alpha_{1}, \beta_{1}, \beta_{2}, \Gamma, N r, N c, \omega$ and $\Lambda$. Here it was observed that $-f^{\prime \prime}(0)$ attained maximum values for $\alpha_{1}, \beta_{1}, \Gamma$ and Nc. From Table 3, the local Nusselt number $-\theta \prime(0)$ has been varied for various involved parameters. An increasing variation in $-\theta \prime(0)$ has been notified with $\beta_{1}, N c$, Pr and $B i$. A restively lower variation in the local Nusselt number was observed for $M, \alpha_{1}$ and $\Gamma$. In Table 4, the trend of local Sherwood number $-\phi \prime(0)$ was specified, which showed that local Sherwood number increase for $N r, N c$ and $L e$. Finally results for motile density number $-\chi^{\prime}(0)$ were executed in Table 5, which shows motile density number get larger values for $\mathrm{Pe}, \mathrm{Lb}$ and $\mathrm{Nc}$.

Table 2. Variation of $-f^{\prime \prime}(0)$ for $M, \alpha_{1}, \beta_{1}, \beta_{2}, \Gamma, N r, N c, \omega$ and $\Lambda$.

\begin{tabular}{|c|c|c|c|c|c|c|c|c|c|}
\hline$M$ & $\alpha_{1}$ & $\beta_{1}$ & $\beta_{2}$ & $\Gamma$ & $\mathrm{Nr}$ & $N c$ & $\omega$ & $\Lambda$ & $-f^{\prime \prime}(0)$ \\
\hline 0.2 & 0.3 & 0.3 & 0.3 & 0.8 & 0.5 & 0.5 & 1 & -1 & 0.3592 \\
\hline 0.6 & & & & & & & & & 0.3566 \\
\hline 1.0 & & & & & & & & & 0.3532 \\
\hline \multirow[t]{24}{*}{0.5} & 0.1 & & & & & & & & 0.3547 \\
\hline & 0.4 & & & & & & & & 0.3573 \\
\hline & 0.7 & & & & & & & & 0.3841 \\
\hline & 0.3 & 0.1 & & & & & & & 0.3374 \\
\hline & & 0.4 & & & & & & & 0.3649 \\
\hline & & 0.7 & & & & & & & 0.3811 \\
\hline & & 0.3 & 0.2 & & & & & & 0.2641 \\
\hline & & & 0.4 & & & & & & 0.2093 \\
\hline & & & 0.6 & & & & & & 0.1733 \\
\hline & & & 0.3 & 0.1 & & & & & 0.3547 \\
\hline & & & & 0.3 & & & & & 0.3555 \\
\hline & & & & 0.5 & & & & & 0.3562 \\
\hline & & & & 0.8 & 0.1 & & & & 0.3584 \\
\hline & & & & & 0.6 & & & & 0.3570 \\
\hline & & & & & 1.0 & & & & 0.3560 \\
\hline & & & & & 0.5 & 0.1 & & & 0.3584 \\
\hline & & & & & & 1.0 & & & 0.3560 \\
\hline & & & & & & 2.0 & & & 0.3570 \\
\hline & & & & & & 0.5 & 2.0 & & 0.2641 \\
\hline & & & & & & & 3.0 & & 0.2093 \\
\hline & & & & & & & 4.0 & & 0.1733 \\
\hline & & & & & & & 1.0 & -2.0 & 0.2836 \\
\hline & & & & & & & & -3.0 & 0.2362 \\
\hline & & & & & & & & -4.0 & 0.2028 \\
\hline
\end{tabular}

Table 3. Variation of $-\theta \prime(0)$ for $M, \alpha_{1}, \beta_{1}, \beta_{2}, \Gamma, N r, N c, \operatorname{Pr}, N t, L e, B i$ and $R d$.

\begin{tabular}{|c|c|c|c|c|c|c|c|c|c|c|c|c|c|}
\hline$M$ & $\alpha_{1}$ & $\beta_{1}$ & $\beta_{2}$ & $\Gamma$ & $\mathrm{Nr}$ & $N c$ & Pr & $\mathrm{Nb}$ & $N t$ & Le & $B i$ & $R d$ & \multirow{2}{*}{$-\theta^{\prime}(0)$} \\
\hline 0.5 & 0.3 & 0.3 & 0.3 & 0.8 & 0.5 & 0.5 & 2.0 & 0.3 & 0.3 & 5.0 & 2.0 & 0.8 & \\
\hline 0.2 & & & & & & & & & & & & & 0.3001 \\
\hline 0.6 & & & & & & & & & & & & & 0.2746 \\
\hline \multirow[t]{17}{*}{1.0} & & & & & & & & & & & & & 0.2549 \\
\hline & 0.1 & & & & & & & & & & & & 0.3062 \\
\hline & 0.4 & & & & & & & & & & & & 0.2693 \\
\hline & 0.7 & & & & & & & & & & & & 0.2904 \\
\hline & & 0.1 & & & & & & & & & & & 0.3158 \\
\hline & & 0.4 & & & & & & & & & & & 0.2670 \\
\hline & & 0.7 & & & & & & & & & & & 0.2377 \\
\hline & & & 0.2 & & & & & & & & & & 0.2829 \\
\hline & & & 0.4 & & & & & & & & & & 0.2778 \\
\hline & & & 0.6 & & & & & & & & & & 0.0374 \\
\hline & & & & 0.1 & & & & & & & & & 0.2356 \\
\hline & & & & 0.4 & & & & & & & & & 0.2079 \\
\hline & & & & 0.7 & & & & & & & & & 0.1893 \\
\hline & & & & & 0.1 & & & & & & & & 0.2784 \\
\hline & & & & & 0.6 & & & & & & & & 0.2808 \\
\hline & & & & & 1.0 & & & & & & & & 0.2827 \\
\hline & & & & & & 0.1 & & & & & & & 0.2681 \\
\hline
\end{tabular}


Table 3. Cont.

\begin{tabular}{|c|c|c|c|c|c|c|c|c|c|c|c|c|c|}
\hline$M$ & $\alpha_{1}$ & $\beta_{1}$ & $\beta_{2}$ & $\Gamma$ & $\mathrm{Nr}$ & $N c$ & Pr & $\mathrm{Nb}$ & $N t$ & Le & $B i$ & $R d$ & \multirow{2}{*}{$-\boldsymbol{\theta}^{\prime}(0)$} \\
\hline \multirow[t]{21}{*}{0.5} & 0.3 & 0.3 & 0.3 & 0.8 & 0.5 & 0.5 & 2.0 & 0.3 & 0.3 & 5.0 & 2.0 & 0.8 & \\
\hline & & & & & & 1.0 & & & & & & & 0.2949 \\
\hline & & & & & & 2.0 & & & & & & & 0.3210 \\
\hline & & & & & & & 1.0 & & & & & & 0.1744 \\
\hline & & & & & & & 3.0 & & & & & & 0.3828 \\
\hline & & & & & & & 5.0 & & & & & & 0.5435 \\
\hline & & & & & & & & 0.1 & & & & & 0.2824 \\
\hline & & & & & & & & 0.3 & & & & & 0.2797 \\
\hline & & & & & & & & 0.5 & & & & & 0.2798 \\
\hline & & & & & & & & & 0.1 & & & & 0.2595 \\
\hline & & & & & & & & & 0.4 & & & & 0.2910 \\
\hline & & & & & & & & & 0.8 & & & & 0.3340 \\
\hline & & & & & & & & & & 1.0 & & & 0.2787 \\
\hline & & & & & & & & & & 2.0 & & & 0.2788 \\
\hline & & & & & & & & & & 3.0 & & & 0.2793 \\
\hline & & & & & & & & & & & 1.0 & & 0.2452 \\
\hline & & & & & & & & & & & 1.4 & & 0.2641 \\
\hline & & & & & & & & & & & 1.8 & & 0.2759 \\
\hline & & & & & & & & & & & & 0.1 & 0.4037 \\
\hline & & & & & & & & & & & & 0.3 & 0.3585 \\
\hline & & & & & & & & & & & & 0.5 & 0.3222 \\
\hline
\end{tabular}

Table 4. Variation of $-\phi \prime(0)$ for $M, \alpha_{1}, \beta_{1}, \beta_{2}, \Gamma, N r, N c, \operatorname{Pr}, N t, L e, B i$ and $R d$.

\begin{tabular}{|c|c|c|c|c|c|c|c|c|c|c|c|c|c|}
\hline$M$ & $\alpha_{1}$ & $\beta_{1}$ & $\beta_{2}$ & $\Gamma$ & $N r$ & $N c$ & Pr & $N b$ & $N t$ & $L e$ & $B i$ & $E$ & \multirow{2}{*}{$-\theta^{\prime}(0)$} \\
\hline 0.5 & 0.3 & 0.3 & 0.3 & 0.8 & 0.5 & 0.5 & 2.0 & 0.3 & 0.3 & 5.0 & 2.0 & 0.1 & \\
\hline 0.2 & & & & & & & & & & & & & 0.4501 \\
\hline 0.6 & & & & & & & & & & & & & 0.4119 \\
\hline \multirow[t]{37}{*}{1.0} & & & & & & & & & & & & & 0.3824 \\
\hline & 0.1 & & & & & & & & & & & & 0.4594 \\
\hline & 0.4 & & & & & & & & & & & & 0.4040 \\
\hline & 0.7 & & & & & & & & & & & & 0.4358 \\
\hline & & 0.1 & & & & & & & & & & & 0.4736 \\
\hline & & 0.4 & & & & & & & & & & & 0.4005 \\
\hline & & 0.7 & & & & & & & & & & & 0.3565 \\
\hline & & & 0.2 & & & & & & & & & & 0.4244 \\
\hline & & & 0.4 & & & & & & & & & & 0.4166 \\
\hline & & & 0.6 & & & & & & & & & & 0.0564 \\
\hline & & & & 0.1 & & & & & & & & & 0.4294 \\
\hline & & & & 0.4 & & & & & & & & & 0.4269 \\
\hline & & & & 0.7 & & & & & & & & & 0.4247 \\
\hline & & & & & 0.1 & & & & & & & & 0.4176 \\
\hline & & & & & 0.6 & & & & & & & & 0.4241 \\
\hline & & & & & 1.0 & & & & & & & & 0.4212 \\
\hline & & & & & & 0.1 & & & & & & & 0.4022 \\
\hline & & & & & & 1.0 & & & & & & & 0.4424 \\
\hline & & & & & & 2.0 & & & & & & & 0.4815 \\
\hline & & & & & & & 1.0 & & & & & & 0.2615 \\
\hline & & & & & & & 3.0 & & & & & & 0.5742 \\
\hline & & & & & & & 5.0 & & & & & & 0.8152 \\
\hline & & & & & & & & 0.1 & & & & & 0.8472 \\
\hline & & & & & & & & 0.3 & & & & & 0.2797 \\
\hline & & & & & & & & 0.5 & & & & & 0.1675 \\
\hline & & & & & & & & & 0.1 & & & & 0.1297 \\
\hline & & & & & & & & & 0.4 & & & & 0.5819 \\
\hline & & & & & & & & & 0.8 & & & & 1.3360 \\
\hline & & & & & & & & & & 1.0 & & & 0.4180 \\
\hline & & & & & & & & & & 2.0 & & & 0.4182 \\
\hline & & & & & & & & & & 3.0 & & & 0.4190 \\
\hline & & & & & & & & & & & 1.0 & & 0.3678 \\
\hline & & & & & & & & & & & 1.4 & & 0.3961 \\
\hline & & & & & & & & & & & 1.8 & & 0.4139 \\
\hline & & & & & & & & & & & & 0.5 & 0.6056 \\
\hline & & & & & & & & & & & & 1.0 & 0.5378 \\
\hline & & & & & & & & & & & & 1.5 & 0.4833 \\
\hline
\end{tabular}


Table 5. Variation of $-\chi^{\prime}(0)$ for $M, \alpha_{1}, \beta_{1}, \beta_{2}, \Gamma, N r, N c, L b$ and $P e$.

\begin{tabular}{|c|c|c|c|c|c|c|c|c|c|}
\hline$M$ & $\alpha_{1}$ & $\beta_{1}$ & $\beta_{2}$ & $\Gamma$ & $\mathrm{Nr}$ & $N c$ & $L b$ & $\mathrm{Pe}$ & \multirow{2}{*}{$-\chi^{\prime}(0)$} \\
\hline 0.5 & 0.3 & 0.3 & 0.3 & 0.8 & 0.5 & 0.5 & 1.0 & 0.1 & \\
\hline 0.2 & & & & & & & & & 0.3620 \\
\hline 0.6 & & & & & & & & & 0.3261 \\
\hline \multirow[t]{25}{*}{1.0} & & & & & & & & & 0.2992 \\
\hline & 0.1 & & & & & & & & 0.3567 \\
\hline & 0.4 & & & & & & & & 0.3244 \\
\hline & 0.7 & & & & & & & & 0.6409 \\
\hline & & 0.1 & & & & & & & 0.3850 \\
\hline & & 0.4 & & & & & & & 0.3155 \\
\hline & & 0.7 & & & & & & & 0.2758 \\
\hline & & & 0.2 & & & & & & 0.3378 \\
\hline & & & 0.4 & & & & & & 0.3305 \\
\hline & & & 0.6 & & & & & & 0.0389 \\
\hline & & & & 0.1 & & & & & 0.3424 \\
\hline & & & & 0.4 & & & & & 0.3401 \\
\hline & & & & 0.7 & & & & & 0.3377 \\
\hline & & & & & 0.1 & & & & 0.3314 \\
\hline & & & & & 0.6 & & & & 0.3348 \\
\hline & & & & & 1.0 & & & & 0.3375 \\
\hline & & & & & & 0.1 & & & 0.3170 \\
\hline & & & & & & 1.0 & & & 0.3548 \\
\hline & & & & & & 2.0 & & & 0.3927 \\
\hline & & & & & & & 0.1 & & 0.1643 \\
\hline & & & & & & & 0.5 & & 0.2378 \\
\hline & & & & & & & 0.8 & & 0.2956 \\
\hline & & & & & & & & 0.2 & 0.3752 \\
\hline & & & & & & & & 0.6 & 0.5399 \\
\hline & & & & & & & & 1.0 & 0.7046 \\
\hline
\end{tabular}

\section{Conclusions}

The salient features of gyrotactic microorganisms in a steady flow of Oldroyd-B nanofluid has been characterized over a stretching cylinder. The convective Nield conditions and second order slip effects are employed for the assumed flow configuration. The developed dimensionless equations are numerically solved by using shooting techniques. Following are the major findings of current numerical work:

* The velocity distribution increases with mixed convection parameter while a decreasing profile of velocity has been observed for mixed convection parameter.

* The interaction of the second order slip reduces the velocity distribution.

* Enhanced temperature distribution is observed for the first order and second order slip factors, thermophoresis constant and curvature parameter.

* The activation energy parameter, thermophoresis parameter, and slip parameter increase the variation in the nanoparticle concentration.

* The motile microorganism distribution decreases with an increase of Peclet number, mixed convection parameter and bioconvection Lewis number.

Author Contributions: I.T.; H.W.; A.A.; S.U.K. and M.I. modeled the problem, numerically computed results, discussed the results physically, computed the tabulated results, wrote the manuscript and proof read it.

Funding: This research received no external funding.

Conflicts of Interest: The authors declare no conflict of interest. 


\section{Nomenclature}

$(u, v, w) \quad$ velocity component

$T \quad$ nanoparticles temperature

$T_{\infty} \quad$ atmospheric temperature

N microorganisms density

$\lambda_{2} \quad$ retardation time

$B \quad$ magnetic field strength

$\rho_{m} \quad$ motile microorganism particles density

$\rho_{f} \quad$ nanoparticles density

$\alpha \quad$ momentum coefficient

$\alpha_{1} \quad$ thermal diffusivity

$D_{T} \quad$ thermophoretic diffusion coefficient

$K_{n} \quad$ Knudsen number

$b_{1} \quad$ chemotaxis constant

$\alpha \quad$ constant Curvature parameter

$\beta_{2} \quad$ Deborah number in terms of retardation time

$\Gamma \quad$ mixed convection parameter

$N_{r} \quad$ buoyancy ratio constant

$R \quad$ thermal radiation parameter

Le Lewis number

Pe Peclet constant

$\Omega_{1} \quad$ bioconvection constant

$\Omega \quad$ second order slip constant

$(r, z) \quad$ cylindrical coordinate

C Concentration profile

$C_{\infty} \quad$ atmospheric concentration

$\lambda_{1} \quad$ relaxation time coefficient,

$\sigma \quad$ electrical conductivity,

g gravity

C volume concentration of magnetic particles,

$T$ nanoparticles temperature,

$\rho_{p} \quad$ liquid density

$D_{B} \quad$ Brownian motion constant,

$W_{c} \quad$ speed of gyrotactic cell,

$(A, B) \quad$ stands for constant,

$\beta \quad$ molecular mean path

$\beta_{1} \quad$ Deborah number in terms of relaxation time

M Hartmann number,

Nc Rayleigh number,

$\mathrm{Nb} \quad$ Brownian motion,

Pr Prandtl number,

$\gamma \quad$ Biot number,

$\mathrm{Lb} \quad$ Lewis number

$\omega \quad$ first order slip constant

Nt thermophoresis parameter

\section{References}

1. Choi, S.U.S. Enhancing thermal conductivity of fluids with nanoparticles. In Developments and Applications of Non-Newtonian Flows; Siginer, D.A., Wang, H.P., Eds.; ASME: New York, NY, USA, 1995; Volume 66, pp. 99-105.

2. Buongiorno, J. Convective transport in nanofluids. J. Heat Transf. 2006, 128, 240-250. [CrossRef]

3. Azam, M.; Khan, M.; Alshomrani, A.S. Effects of magnetic field and partial slip on unsteady axisymmetric flow of Carreaunanofluid over a radially stretching surface. Results Phys. 2017, 7, 2671-2682. [CrossRef] 
4. Alblawi, A.; Malik, M.Y.; Nadeem, S.; Abbas, N. Buongiorno'sNanofluid Model over a Curved Exponentially Stretching Surface. Processes 2019, 7, 665. [CrossRef]

5. Elgazery, N.S. Nanofluids flow over a permeable unsteady stretching surface with non-uniform heat source/sink in the presence of inclined magnetic field. J. Egypt. Math. Soc. 2019, 27, 9.

6. Hayat, T.; Aziz, A.; Muhammad, T.; Alsaedi, A. Active and passive controls of Jeffrey nanofluid flow over a nonlinear stretching surface. Results Phys. 2017, 7, 4071-4078. [CrossRef]

7. Gireesha, B.J.; Mahanthesh, B.; Thammanna, G.T.; Sampathkumar, P.B. Hall effects on dusty nanofluid two-phase transient flow past a stretching sheet using KVL model. J. Mol. Liq. 2018, 256, 139-147. [CrossRef]

8. Hamid, A.; Khan, M. Heat and mass transport phenomena of nanoparticles on time dependent flow of Williamson fluid towards heated surface. Neural Comput. Appl. 2019. [CrossRef]

9. Waqas, H.; Imran, M.; Khan, S.U.; Shehzad, S.A.; Meraj, M.A. Slip flow of Maxwell viscoelasticity-based micropolarnano particles with porous medium: A numerical study. Appl. Math. Mech. 2019, 40, 1255-1268. [CrossRef]

10. Turkyilmazoglu, M. Free and circular jets cooled by single phase nanofluids. Eur. J. Mech. B/Fluids 2019, 76, 1-6. [CrossRef]

11. Rafiq, M.; Yasmin, H.; Hayat, T.; Alsaadi, F. Effect of Hall and ion-slip on the peristaltic transport of nanofluid: A biomedical application. Chin. J. Phys. 2019, 60, 208-227. [CrossRef]

12. Tlili, I.; Khan, W.A.; Ramadan, K. MHD Flow of Nanofluid Flow Across Horizontal Circular Cylinder: Steady Forced Convection. J. Nanofluids 2019, 8, 179-186. [CrossRef]

13. Alzahrani, E.O.; Shah, Z.; Alghamdi, W.; Ullah, M.Z. Darcy-Forchheimer Radiative Flow of Micropoler CNT Nanofluid in Rotating Frame with Convective Heat Generation/Consumption. Processes 2019, 7, 666. [CrossRef]

14. Ul Rahman, J.; Khan, U.; Ahmad, S.; Ramzan, M.; Suleman, M.; Lu, D.; Inam, S. Numerical Simulation of Darcy-Forchheimer 3D Unsteady Nanofluid Flow Comprising Carbon Nanotubes with Cattaneo-Christov Heat Flux and Velocity and Thermal Slip Conditions. Processes 2019, 7, 687. [CrossRef]

15. Mozaffari, S.; Tchoukov, P.; Atias, J.; Czarnecki, J.; Nazemifard, N. Effect of Asphaltene Aggregation on Rheological Properties of Diluted Athabasca Bitumen. Energy Fuels 2015, 29, 5595-5599. [CrossRef]

16. Mozaffari, S.; Li, W.; Dixit, M.; Seifert, S.; Lee, B.; Kovarik, L.; Mpourmpakis, G.; Karim, A.M. The role of nanoparticle size and ligand coverage in size focusing of colloidal metal nanoparticles. Nanoscale Adv. 2019, 1, 4052-4066. [CrossRef]

17. Mozaffari, A.; Sharifi-Mood, N.; Koplik, J.; Maldarelli, C. Self-diffusiophoretic colloidal propulsion near a solid boundary. Phys. Fluids 2016, 28, 053107. [CrossRef]

18. Mozaffari, S.; Tchoukov, P.; Mozaffari, A.; Atias, J.; Czarnecki, J.; Nazemifard, N. Capillary driven flow in nanochannels-Application to heavy oil rheology studies. Colloids Surf. A Physicochem. Eng. Asp. 2017, 513, 178-187. [CrossRef]

19. Hashmi, M.S.; Khan, N.; Khan, S.U.; Rashidi, M.M. A Mathematical model for mixed convective flow of chemically reactive Oldroyd-B fluid between isothermal stretching disks. Results Phys. 2017, 7, 3016-3023. [CrossRef]

20. Khan, S.U.; Shehzad, S.A.; Nasir, S. Unsteady flow of chemically reactive Oldroyd-B fluid over oscillatory moving surface with thermo-diffusion and heat absorption/generation effects. J. Braz. Soc. Mech. Sci. Eng. 2019, 41, 72. [CrossRef]

21. Irfan, M.; Khan, M.; Khan, W.A. Impact of non-uniform heat sink/source and convective condition in radiative heat transfer to Oldroyd-B nanofluid: A revised proposed relation. Phys. Lett. A 2019, 383, 376-382. [CrossRef]

22. Khan, S.U.; Ali, N. Unsteady Hydromagnetic Flow of Oldroyd-B Fluid over an Oscillatory Stretching Surface: A Mathematical Model. Tech. Sci. 2017, 20, 87-100. [CrossRef]

23. Kumar, K.G.; Ramesh, G.K.; Gireesha, B.J.; Gorla, R.S.R. Characteristics of Joule heating and viscous dissipation on three-dimensional flow of Oldroyd B nanofluid with thermal radiation. Alex. Eng. J. 2018, 57, 2139-2149. [CrossRef]

24. Waqas, M.; Khan, M.I.; Hayat, T.; Alsaedi, A. Stratified flow of an Oldroyd-B nano-liquid with heat generation. Results Phys. 2017, 7, 2489-2496. [CrossRef]

25. Mehmood, R.; Rana, S.; Nadeem, S. Transverse thermopherotic MHD Oldroyd-B fluid with Newtonian heating. Results Phys. 2018, 8, 686-693. [CrossRef] 
26. Kuznetsov, A.V. The onset of nanofluidbioconvection in a suspension containing both nanoparticles and gyrotactic microorganisms. Int. Commun. Heat Mass Transf. 2010, 37, 1421-1425. [CrossRef]

27. Kuznetsov, A.V. Nanofluidbioconvection in water-based suspensions containing nanoparticles and oxytactic microorganisms: Oscillatory instability. Nanoscale Res. Lett. 2011, 6, 100. [CrossRef]

28. Chakraborty, T.; Das, K.; Kundu, P.K. Framing the impact of external magnetic field on bioconvection of a nanofluid flow containing gyrotactic microorganisms with convective boundary conditions. Alex. Eng. J. 2018, 57, 61-71. [CrossRef]

29. Alsaedi, A.; Khan, M.I.; Farooq, M.; Gull, N.; Hayat, T. Magnetohyrodynamic (MHD) stratified bio-convective flow of nanofluid due to gyrotactic microorganisms. Adv. Powder Technol. 2017, 28, 288-298. [CrossRef]

30. Khan, W.A.; Uddin, M.J.; Ismail, A.I.M. Free convection of non-Newtonian nanofluids in porous media with gyrotactic microorganisms. Trans. Porous Med. 2013, 97, 241-252. [CrossRef]

31. Xun, S.; Zhao, J.; Zheng, L.; Zhang, X. Bio convection in rotating system immersed in nanofluid with temperature dependent viscosity and thermal conductivity. Int. J. Heat Mass Transf. 2017, 111, 1001-1006. [CrossRef]

32. Beg, O.A.; Uddin, M.D.J.; Khan, W.A. Bioconvective non-Newtonian nanofluid transport in porous media containing micro-organisms in a moving free stream. J. Mech. Med. Biol. 2015, 15, 1550071. [CrossRef]

33. Waqas, H.; Khan, S.U.; Imran, M.; Bhatti, M.M. Thermally developed Falkner-Skanbioconvection flow of a magnetized nanofluid in the presence of motile gyrotactic microorganism: Buongiorno's nanofluid model. Phys. Scr. 2019, 94, 115304. [CrossRef]

34. ZamanMahwishGul, S. Magnetohydrodynamicbioconvective flow of Williamson nanofluid containing gyrotactic microorganisms subjected to thermal radiation and Newtonian conditions. J. Theor. Biol. 2019, $479,22-28$.

35. Ur Rehman, K.; Malik, A.A.; Tahir, M.; Malik, M.Y. Undersized description on motile gyrotactic micro-organisms individualities in MHD stratified water-based Newtonian nanofluid. Results Phys. 2018, 8, 981-987. [CrossRef]

36. Bhatti, M.M.; Mishra, S.R.; Abbas, T.; Rashidi, M.M. A mathematical model of MHD nanofluid flow having gyrotactic microorganisms with thermal radiation and chemical reaction effects. Neural Comput. Appl. 2018, 30, 1237-1249. [CrossRef]

37. Wu, L. A slip model for rarefied gas flows at arbitrary Knudsen number. Appl. Phys. Lett. 2008, 93, 253103. [CrossRef]

38. Nandeppanavar, M.M.; Vajravelu, K.; Abel, M.S.; Siddalingappa, M. Second order slip flow and heat transfer over a stretching sheet with non-linear Navier boundary condition. Int. J. Therm. Sci. 2012, 58, 143-150. [CrossRef]

39. Khan, S.U.; Waqas, H.; Shehzad, S.A.; Imran, M. Theoretical analysis for tangent hyperbolic nanoparticles with combined electrical MHD, activation energy and Wu's slip features: A mathematical model. Phys. Scr. 2019, 94, 125211. [CrossRef]

40. Ibrahim, W. Magnetohydrodynamics (MHD) flow of a tangent hyperbolic fluid with nanoparticles past a stretching sheet with second order slip and convective boundary condition. Results Phys. 2017, 7, 3723-3731. [CrossRef]

41. Abel, M.S.; Tawade, J.V.; Nandeppanavar, M.M. MHD flow and heat transfer for the upper-convected Maxwell fluid over a stretching sheet. Meccanica 2012, 47, 385-393.

42. Megahed, A.M. Variable fluid properties and variable heat flux effects on the flow and heat transfer in a non-Newtonian Maxwell fluid over an unsteady stretching sheet with slip velocity. Chin. Phys. B 2012, 22, 094701. [CrossRef]

43. Irfan, M.; Khan, M.; Khan, W.A.; Sajid, M. Thermal and solutal stratifications in flow of Oldroyd-B nanofluid with variable conductivity. Appl. Phys. A 2018, 124, 674. [CrossRef]

44. Atif, S.M.; Hussain, S.; Sagheer, M. Effect of viscous dissipation and Joule heating on MHD radiative tangent hyperbolic nanofluid with convective and slip conditions. J. Braz. Soc. Mech. Sci. Eng. 2019, 41, 189. [CrossRef]

45. Tlili, I. Effects MHD and Heat Generation on Mixed Convection Flow of Jeffrey Fluid in Microgravity Environment over an Inclined Stretching Sheet. Symmetry 2019, 11, 438. [CrossRef] 
46. Goodarzi, M.; Tlili, I.; Tian, Z.; Safaei, M. Efficiency assessment of using graphene nanoplatelets-silver/water nanofluids in microchannel heat sinks with different cross-sections for electronics cooling. Int. J. Numer. Methods Heat Fluid Flow 2019. [CrossRef]

47. Tlili, I.; Alkanhal, T.A. Nanotechnology for water purification: Electrospun nanofibrous membrane in water and wastewater treatment. J. Water Reuse Desalin. 2019, 24. [CrossRef]

48. Tlili, I.; Khan, W.A.; Khan, I. Multiple slips effects on MHD SA-Al2O3 and SA-Cu Non-Newtonian nanofluids flow over a stretching cylinder in porous medium with radiation and chemical reaction. Results Phys. 2018, 8, 213-222. [CrossRef]

49. Tlili, I.; Hamadneh, N.N.; Khan, W.A. Thermodynamic Analysis of MHD Heat and Mass Transfer of Nanofluids Past a Static Wedge with Navier Slip and Convective Boundary Conditions. Arab. J. Sci. Eng. 2018, 44, 1255-1267. [CrossRef]

50. Tlili, I.; Hamadneh, N.N.; Khan, W.A.; Atawneh, S. Thermodynamic analysis of MHD Couette-Poiseuille flow of water-based nanofluids in a rotating channel with radiation and Hall effects. J. Therm. Anal. Calorim. 2018, 132, 1899-1912. [CrossRef]

51. Alwatban, A.M.; Khan, S.U.; Waqas, H.; Tlili, I. Interaction of Wu's slip features in bioconvection of Eyring Powell nanoparticles with activation energy. Processes 2019, 7, 859. [CrossRef]

52. Waqas, H.; Khan, S.U.; Hassan, M.; Bhatti, M.M.; Imran, M. Analysis for bioconvection flow of modified second grade fluid containing gyrotactic microorganisms and nanoparticles. J. Mol. Liq. 2019, 291, 111231. [CrossRef]

(C) 2019 by the authors. Licensee MDPI, Basel, Switzerland. This article is an open access article distributed under the terms and conditions of the Creative Commons Attribution (CC BY) license (http://creativecommons.org/licenses/by/4.0/). 